\title{
Fourier Transform Infrared Spectroscopy and Scanning Electron Microscopy Characterization of Adhesive Produced From Polystyrene Waste
}

\author{
Lucas Albert Jerome Hamidu ${ }^{1}$, Umar Omeiza Aroke ${ }^{2}$, Odeh Adey Osha ${ }^{2}$, \\ Idris Misau Muhammad ${ }^{2}$
}

${ }^{1}$ Nigerian Building and Road Research Institute

10 NBRRI Way / I.T. Igbani Street, off Awolowo Way, Jabi, Abuja, Nigeria

${ }^{2}$ Abubakar Tafawa Balewa University

Tafawa Balewa Way, P. M. B. 0248, Bauchi, 740272, Nigeria

DOI: $10.22178 /$ pos.53-4

LCC Subject Category: QD1-65

Received 28.11.2019

Accepted 25.12.2019

Published online 31.12.2019

Corresponding Author:

Lucas Albert Jerome Hamidu

lucadohamidu@yahoo.com

(C) 2019 The Authors. This article

is licensed under a Creative

Commons Attribution 4.0 License

(c) (1)

\begin{abstract}
In this study, the optimized adhesive formulated from polystyrene waste was characterized for Fourier transform infrared (FTIR) spectra, Scanning Electron Microscopy (SEM) / Energy Dispersive X-ray (EDX) spectroscopy, solubility, density and water absorption for identification of existing functional group(s), morphology, elemental compositions, etc. The results revealed that polystyrene, unsaturated hydrocarbon has been degraded to form a new product containing aromatic compounds. SEM morphology showed well mixed blended adhesive with silver-like appearance due to additives and EDX revealed 12 existing elemental compositions with their corresponding percentage atomic weights as follows; carbon $93.14 \%$, hafnium $1.44 \%$, vanadium $1.66 \%$, chromium $1.40 \%$, bromine $0.47 \%$, palladium $0.26 \%$, copper $0.43 \%$, nickel $0.31 \%$, cobalt $0.29 \%$, potassium $0.38 \%$, iron $0.15 \%$ and manganese $0.08 \%$. The produced polystyrene adhesive was sparsely soluble in water after 30 minutes; it has a density of $1041 \mathrm{~kg} / \mathrm{m} 3$ and does not absorb moisture. Because of these results, the adhesive from polystyrene waste could serve as green adhesive, since there are no threats of toxic substance emission from the spectral analysis since most of the elements are used as a supplement in pharmaceuticals and catalyst in process industries.
\end{abstract}

Keywords: Adhesive; Characterization; scanning electron microscopy / energy dispersive X-ray; Fourier Transform Infrared Spectroscopy; Polystyrene Waste.

\section{INTRODUCTION}

The general view of the conversion of waste to wealth is propelling researchers into the utilization of abundant waste materials regarded as not valuable. The use of green and non-emitting materials in providing a sustainable environment is objectionable considering the globalization of climate change threats. The adhesive is substances that stick to one or more substrates that become bonded when surfaces are wetted and covalently joined together [15, 27]. Adhesive sources are either natural or synthetic, the natural types of adhesive are from the animal bore, casein; plants, etc. and while synthetic are produced from industrial chemicals [15].

Most adhesives used in composites materials production are synthetic and have medical con- cern due to emissions from its users which makes it not environmentally friendly, and are reported carcinogenic due to the presence of formaldehyde derivatives [3, 14, 29, 10]. In a bid to develop environmentally friendly adhesive devoid of any side effects, additives such as plasticizers from diblend or triblend of diethylene glycol dibenzoate and dipropylene glycol dibenzoate are usually added for stabilization of its properties for ease application $[6,5]$.

Authors [15] formulated and characterized adhesive from polystyrene waste using response surface optimization for their; viscosities, $\mathrm{pH}$, solid and moisture content. However; elemental composition, functional groups and other physicochemical properties were not determined to establish the potentials and safe usage of the produced adhesive. 
In this research, the best-formulated adhesive by [15] was optimized and further characterization for; Fourier transforms infrared spectroscopy (FT-IR), Scanning Electron Microscopy (SEM), solubility in water, water absorption and density to fully understand the functional groups and mineralogical composition of the produced adhesive for sustainable green environment.

Fourier transforms infrared (FT-IR) spectra instrument has been used to study the existence of different compounds in a mixture [24]. It is the ideal process of identification and analyzing chemical components in unknown materials, qualitatively or consistency of samples and amount of components in a mixture [4]. Functional groups are identified within the ranges of $4000-1300 \mathrm{~cm}^{-1}$ bands and fingerprints are in the ranges of $1300-400 \mathrm{~cm}^{-1}$ bands when radiated $[7,28,13,22,8,1$, 9]. Several types of research carried out in the past used FT-IR technique to study characteristic properties and functional groups of different compounds [17, 21]. Authors [29] used FT-IR to characterize native starch, oxidized starch; U-O-st adhesive and nano- $\mathrm{TiO}_{2}$-U-Ost adhesive to determine the existing functional groups dominating during the oxidation processes. Researchers [4] applied FT-IR instrument to study the transmission spectra of laser dye, polystyrene and Coumarin chemical structure and bonds. Authors [10] used FT-IR to study the "characterization of the ureaformaldehyde (UF) resins modified with styrenemaleic amic acid (SMAA) derivatives". The primary major differences between the modified and unmodified starch adhesive sample for carboxymethyl starch and particleboard samples was examined using FT-IR [26]. Authors [18] used FT-IR to study different existing functional groups in the development of urea formaldehyde and polystyrene waste copolymer binder for emulsion paint formulation. Researchers [25] study by FT-IR Technique and adhesive properties of vulcanized EPDM modified with plasma. These are some of the studies carried out using FT-IR in studying and evaluation of characteristic functional group, and interpretation of organic compounds.

A scanning electron microscope is a device that identifies samples image by scanning with a highresolution energy beam of electrons in a raster scan patterns. The electron interacts with the atoms that make up the samples producing signals containing information about the surface topology of the system, sample composition, proper- ties such as electrical conductivities and quantitative measurement of the object [23]. It is a wellestablished method of observing the morphology of the sample adhered to materials surfaces and the relationship between them [11]. In most cases, the SEM is used in conjunction with the energy-dispersive X-ray spectroscopy (EDS or EDX) to determine the elemental composition of a sample. Adhesive solubility would be carried out according to the standard procedure $[2,19$, 16], density [16] and moisture absorption [2, 19, 20] would be determined.

\section{MATERIALS AND METHODS}

Polystyrene waste was collected from commercial outlets in Bauchi metropolis, the tackifyer was obtained from Total Filling station, Yelwa. The reagents used are; diphenylamine $(99.9 \%$ purity), diethylene glycol dibenzoate $(99.8 \%$ purity) BDH Chemical and absolute ethanol (98$99 \%$ purity) Netherlands GPR were purchased from a local vendor. The equipment used was digital weighing balance model PGW 45021, mechanical stirrer model Heidolph 50111 and measuring cylinders. Fourier transform infrared model FT-IR-8400S, Schmadu and Sputter Coater Q150T UK model.

The following processes were used in the development of adhesive from polystyrene waste and its characterization according to [15].

Fourier Transform Infrared Spectroscopy (FTIR) analysis. FTIR analysis of the produced adhesive was carried out using FT-IR-8400S, SHIMADU model. The potassium bromide (KBr) and produced polystyrene adhesive were mixed $[29,17]$. This was followed by a beam of light reflection on the sample converted to transmission spectra for the results within the frequency ranges of 4000$750 \mathrm{~cm}^{-1}[29,28,13]$. The sample was scanned 10 times at $2 \mathrm{~cm}^{-1}$ resolution for data precision and accuracy.

Scanning Electron Microscope (SEM) Characterization. The SEM study was carried out in conjunction with energy dispersive X-ray spectroscopy (EDX) on the produced adhesive for morphology and elemental compositions, using SEM machine model sputter coater Q150T by Quorum UK. The produced adhesive sample was first placed on a double adhesive on the sample stub; thereafter it was placed in a sputter coater followed by deposition of $5 \mathrm{~nm}$ gold on the produced adhesive sample and finally introduced 
into the SEM machine column for analysis at different magnifications, and the resulted data was stored and exported to the software [29, 26].

Solubility in Water. The produced adhesive solubility in water was determined according to [2, 19]. $5 \mathrm{~g}$ of produced adhesive was placed in a 40 $\mathrm{ml}$ graduated cylinder, then followed by the addition of $20 \mathrm{ml}$ of distilled water at room temperature and allowed to stay for 30 minutes by physical observation. The colour of the distilled water was sparsely brown. After 30 minutes the produced adhesive was removed and weighed. The new weight of the produced adhesive was weighing $4.99 \mathrm{~g}$.

Density. The density of the produced adhesive was carried out according to [16]. $5 \mathrm{~g}$ of produced adhesive was weighed and added to $20 \mathrm{ml}$ of distilled water in the graduated cylinder, the volume of the distilled water change from 20 to $24.8 \mathrm{ml}$.

Determination of Moisture Absorption. The moisture uptake of the produced adhesive was determined according to $[2,20]$ using the gravimetric method. $5 \mathrm{~g}$ of Produced adhesive was weighed and placed inside a desiccator containing a saturated solution of sodium chloride and allowed to stay for $1 \mathrm{hr}$. After the period, the produced adhesive was removed and reweighed to determine the moisture absorbed, the difference between the dry and wet sample is the amount of moisture the adhesive absorbed.

\section{RESULTS AND DISCUSSION}

Fourier Transform Infrared (FTIR) Spectra of Produced Adhesive. The FTIR functional group test result for the best-fitted adhesive showing the absorbance spectra at different peaks as shown in Figure 1 is presented in Table 1.

Figure 1 shows the detailed absorbance of the spectra at different waveband. The absorbance peaks were located in the wide range of spectral scale between $4000-750 \mathrm{~cm}^{-1}$ wavelength [13]. There are 22 peaks in the spectra spreading across the entire wavelength showing different functional groups.

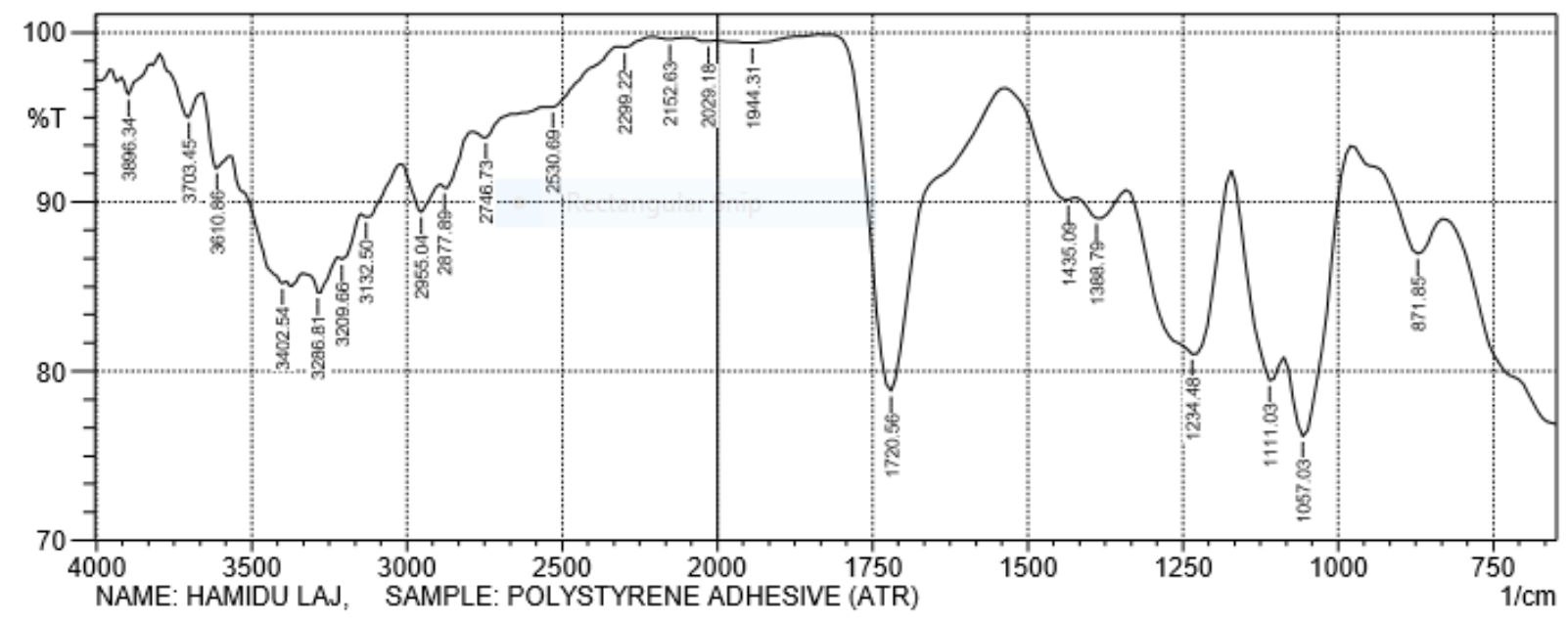

Figure 1 - Fourier Transform Infrared Spectra of Polystyrene Adhesive

Three peaks were located in the range of 40003500 with the absorbance at (3896.34, 3703.45 and $3610.86 \mathrm{~cm}^{-1}$ corresponding to $\mathrm{O}-\mathrm{H}$ band stretching vibrations with free hydroxyl group usually assigning to alcohols and phenols [17], which could be due to the additives in the formulation. Four peaks were located in the range $3500-3000 \mathrm{~cm}^{-1}$ with absorbance at (3402.54, $3286.81,3209.66$ and 3132.50 ) assign to $\mathrm{N}-\mathrm{H}$ stretching vibrations presence of amines functional group due to the presence of diphenyl amines $[24,25]$. Four peaks were located in the region 3000-2500 $\mathrm{cm}^{-1}$ with absorbance at (2955.04, 2877.89, 2746.73 and 2530.69) $\mathrm{cm}^{-1}$ vibrations assign to $\mathrm{O}-\mathrm{H}$ stretching usually for carboxylic acid region, $\mathrm{H}-\mathrm{C}=\mathrm{O}: \mathrm{C}-\mathrm{H}$ stretching assign to aldehydes region and $\mathrm{C}-\mathrm{H}$ stretching alkanes revealed presence of saturated hydrocarbon produced from the oxidation of aldehydes $[28,13]$. 
Table 1 - Fourier Transform Infrared (FTIR) Spectra of Produced Adhesive

\begin{tabular}{|c|c|c|c|}
\hline Peaks & Intensity & Bond & $\begin{array}{c}\text { Functional } \\
\text { group/fingerprint }\end{array}$ \\
\hline 871.85 & 86.945 & $\mathrm{C}-\mathrm{H}$ & Aromatics \\
\hline 1057.03 & 76.16 & $\begin{array}{l}\mathrm{C}-\mathrm{N} \\
\text { stretch }\end{array}$ & Aliphatic amines \\
\hline 1111.03 & 79.475 & $\begin{array}{l}\mathrm{C}-\mathrm{N} \\
\text { stretch }\end{array}$ & Aliphatic amines \\
\hline 1234.48 & 80.997 & $\begin{array}{l}\mathrm{C}-\mathrm{N} \\
\text { stretch }\end{array}$ & Aliphatic amines \\
\hline 1435.09 & 90.128 & $\begin{array}{l}\text { C-C } \\
\text { stretch } \\
\text { (in-ring) }\end{array}$ & Aromatics \\
\hline 1720.56 & 78.813 & $\begin{array}{l}\mathrm{C}=0 \\
\text { stretch }\end{array}$ & $\begin{array}{l}\text { Aldehydes, satu- } \\
\text { rated aliphatic }\end{array}$ \\
\hline 2152.63 & 99.621 & $\begin{array}{l}\text {-C(triple } \\
\text { bond)C- } \\
\text { stretch }\end{array}$ & Alkynes \\
\hline 2746.73 & 93.82 & $\begin{array}{l}\mathrm{H}-\mathrm{C}=\mathrm{O}: \\
\mathrm{C}-\mathrm{H} \\
\text { stretch }\end{array}$ & Aldehydes \\
\hline 2877.89 & 90.83 & $\begin{array}{l}\mathrm{C}-\mathrm{H} \\
\text { stretch }\end{array}$ & Alkanes \\
\hline 2955.04 & 89.413 & $\begin{array}{l}\mathrm{C}-\mathrm{H} \\
\text { stretch }\end{array}$ & Alkanes \\
\hline 3132.5 & 89.125 & $\begin{array}{l}\text { O-H } \\
\text { stretch }\end{array}$ & Carboxylic acids \\
\hline 3209.66 & 86.617 & $\begin{array}{l}\text { O-H } \\
\text { stretch }\end{array}$ & Carboxylic acids \\
\hline 3286.81 & 84.638 & $\begin{array}{l}\mathrm{O}-\mathrm{H} \\
\text { stretch }\end{array}$ & Carboxylic acids \\
\hline 3402.54 & 85.202 & $\begin{array}{l}\mathrm{O}-\mathrm{H} \\
\text { stretch, } \\
\mathrm{H}- \\
\text { bonded }\end{array}$ & Alcohols, phenols \\
\hline 3610.86 & 92.01 & $\begin{array}{l}\text { O-H } \\
\text { stretch, } \\
\text { free hy- } \\
\text { droxyl }\end{array}$ & Alcohols, phenols \\
\hline 3702.45 & 95.041 & $\begin{array}{l}\text { O-H } \\
\text { stretch, } \\
\text { free hy- } \\
\text { droxyl }\end{array}$ & Alcohols, phenols \\
\hline 3896.34 & 96.364 & $\begin{array}{l}\text { O-H } \\
\text { stretch, } \\
\text { free hy- } \\
\text { droxyl }\end{array}$ & Alcohols, phenols \\
\hline
\end{tabular}

Three peaks were located in the region of 2500-2000 $\mathrm{cm}^{-1}$ with absorbance at (2299.22, 2152.63 and 2029.18$) \mathrm{cm}^{-1}$ with no functional group assigned to the region. In the region of $2000-1750 \mathrm{~cm}^{-1}$, there was only a peak located at $1944.31 \mathrm{~cm}^{-1}$ absorbances without any functional group assigned from the vibrated absorbance. Also, a peak was located between $1750-1500 \mathrm{~cm}^{-1}$ at $1720.56 \mathrm{~cm}^{-1}$ assigned to amides (esters) $\mathrm{C}=0$ stretching vibrational band of aromatic compound [12]. Two peaks were located between $1500-1250 \mathrm{~cm}^{-1}$ at (1435.09, 1388.79) C-C stretching (in-ring) assigned to the aromatics functional group [7, $12]$. From the ranges of $1500-400 \mathrm{~cm}^{-1}$ is the fingerprint region [13], where three peaks were located in the range of $1250-1000 \mathrm{~cm}^{-1}$ with absorbance at (1111.03 and 1057.03$) \mathrm{cm}^{-1}$ assign to C-N stretching vibrations band of aliphatic amines with sharp bends at $1057.03 \mathrm{~cm}^{-1}$ absorbances and $871.85 \mathrm{~cm}^{-1}$ peaks was assign for primary, secondary amines and aromatic N-H wag and $\mathrm{C}-\mathrm{H}$ located between $1000-750 \mathrm{~cm}^{-1}$ $[24,7,28]$.

The results from FTIR spectra revealed the conversion of polystyrene waste to adhesive attainment was achieved. The polystyrene formation which makes it unsaturated aromatic hydrocarbon had carbon $=$ carbon double bond $(\mathrm{C}=\mathrm{C})$ functional group [4] covalently joined together with the additives to form saturated hydrocarbon with C-C stretching aromatics and C-N stretching aliphatic functional group. This implies that PS structure converted to the new product due to diphenylamine and diethylene glycol dibenzoate additive. The presence of hindered amines antioxidants in the formulation attributed to sparse solubility of the produced adhesive in water. The $\mathrm{O}-\mathrm{H}$ functional group in the adhesive assign to alcohols and phenols were due to the tackifier and plasticizers covalently shared to form a strong bond. The aldehyde identified in the band was reduced to alcohol in the presence of antioxidants resulting in carbonyl and hydroxyl functional groups. Thus, the produced adhesive can form a strong bond as it is ready to protonate the hydroxyl bond.

The FTIR result for polystyrene adhesive is presented in Table 1 showing absorbance peaks for the spectra.

Scanning Electron Microscope (SEM) of Polystyrene Produced Adhesive. Figure 2 presents the SEM microstructure of produced adhesive from polystyrene waste. 


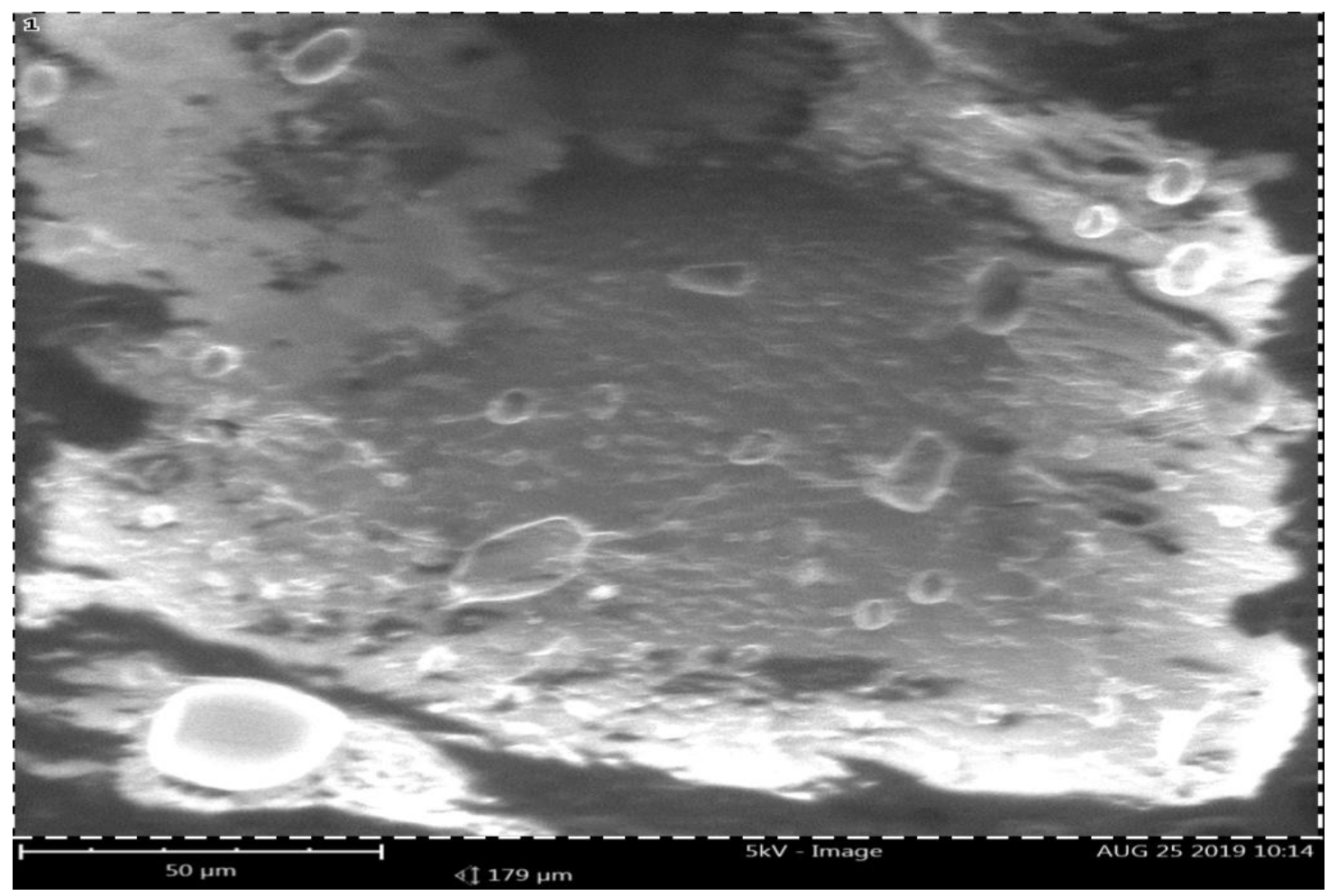

Figure 2 - Scanning Electron Microscopy of Polystyrene Adhesive

The scanning electron microscopy (SEM) of the produced polystyrene adhesive (PPA) was carried out as presented in Figure 2. The micrograph formation of the produced adhesive was in a smooth form with some spherical particles smoothly aggregated together in silver like appearance. From Figure 2, it can be adjudged that, the additives plasticizer (diethylene glycol dibenzoate) and antioxidant (diphenylamine) blended adequately to maintain its plastic nature. The produced adhesive with low moisture content shows disappearance of water bubbles on the morphology, this has also contributed to the stability of the adhesive and improved properties for a green adhesive using green plasticizer in the stabilization [5].

Energy Dispersive X-ray (EDX) of Polystyrene Produced Adhesive. Figure 3 presents the EDX spectra of the produced adhesive from polystyrene waste.

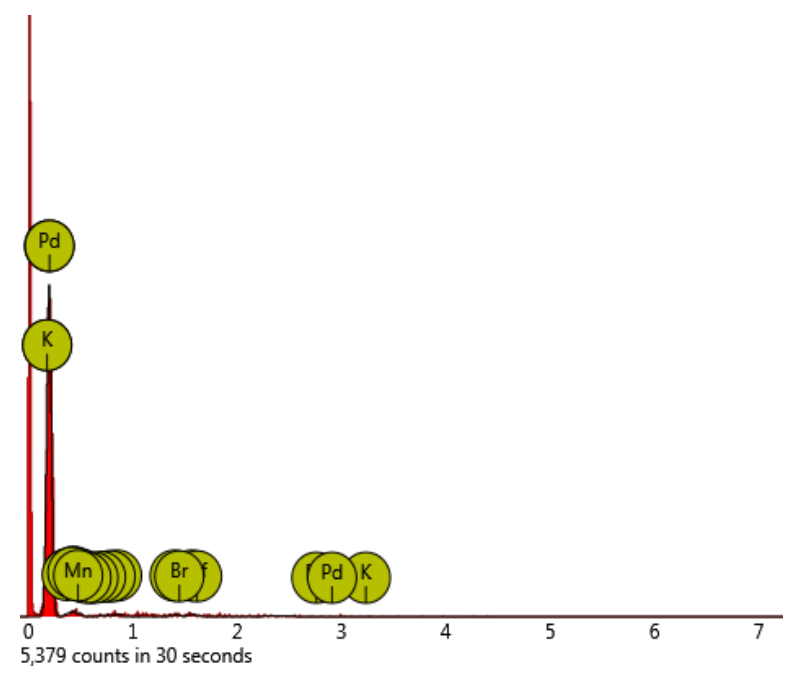

Figure 3 - Energy Dispersive X-ray Spectra of Polystyrene Adhesive 
EDX spectrum analysis of the produced adhesive was carried out to identify the existing elemental compositions for their toxicity and friendliness. This is because most adhesive used in composites and particleboard productions are not friendly as they are carcinogenic [3]. The EDX spectra identified 12 elements in the produced adhesive as presented in Table 2 . These elements are; carbon being the dominant, hafnium, vanadium, chromium, bromine, palladium, copper, nickel, cobalt, potassium, iron and manganese. Some of these elements have been used as supplements in pharmaceutical and catalyst respectively.

Table 2 - Elemental Composition of Produced Adhesive from Polystyrene wastes

\begin{tabular}{|l|l|c|c|}
\hline Symbol & Name & $\begin{array}{c}\text { Conc. } \\
\text { Atomic, \% }\end{array}$ & $\begin{array}{c}\text { Conc. } \\
\text { Weight, \% }\end{array}$ \\
\hline $\mathrm{C}$ & Carbon & 93.14 & 66.29 \\
\hline $\mathrm{Hf}$ & Hafnium & 1.44 & 15.19 \\
\hline $\mathrm{V}$ & Vanadium & 1.66 & 5.02 \\
\hline $\mathrm{Cr}$ & Chromium & 1.40 & 4.33 \\
\hline $\mathrm{Br}$ & Bromine & 0.47 & 2.25 \\
\hline $\mathrm{Pd}$ & Palladium & 0.26 & 1.62 \\
\hline $\mathrm{Cu}$ & Copper & 0.43 & 1.62 \\
\hline $\mathrm{Ni}$ & Nickel & 0.31 & 1.07 \\
\hline $\mathrm{Co}$ & Cobalt & 0.29 & 1.00 \\
\hline $\mathrm{K}$ & Potassium & 0.38 & 0.87 \\
\hline $\mathrm{Fe}$ & Iron & 0.15 & 0.50 \\
\hline $\mathrm{Mn}$ & Manganese & 0.08 & 0.25 \\
\hline & & 100.00 & 100.00 \\
\hline
\end{tabular}

Elemental Compositions of Polystyrene Produced Adhesive. The elemental composition of produced adhesive from polystyrene waste is presented in Table 2 showing various elements existing from the investigation.
The Solubility of produced Adhesive in Water. Adhesive solubility in water is important since it determines the permeability and resistance to ease disappearance. It was observed that, after 30 minutes of adding distilled water, the produced adhesive was sparsely soluble in the water showing brownish colour amounting to $0.01 \mathrm{~g}$ reduction from the original weight.

The Density of Produced Adhesive. The density of the produced adhesive was determined according to [16]. The result was that the produced adhesive has a density of $1042 \mathrm{~kg} / \mathrm{m}^{3}$ which is denser than water.

Moisture Absorption of Produced Adhesive. The moisture absorption of the produced adhesive was found to be -0.02 , which implies that the produced adhesive does not absorb moisture.

\section{CONCLUSION}

The optimized adhesive formulated from polystyrene waste was further characterized by FTIR, SEM/EDX, density, and moisture absorption. The produced adhesive has a density of $1042 \mathrm{~kg} / \mathrm{m}^{3}$. The identified functional groups from the spectra are mainly; aromatic compounds, amines, and hydroxyl. The polystyrene structure has been degraded into adhesive; SEM and EDX analysis revealed 12 elements were found in the produced adhesive which is non-toxic and harmful to living organisms as some are used as supplements in pharmaceuticals and catalysts in the processing industry.

\section{Acknowledgments}

The authors gratefully thank Nigerian Building and Road Research Institute, for raw materials Processing and Abubakar Tafawa Balewa University for allowing this work to be carried out at no cost.

\section{REFERENCES}

1. Adjova, E., Olodo, E., \& Doko, V. (2018). Study of the implementation of waste wood, plastics and polystyrene from industries for various applications in the building industry. Retrieved from http://challengest.scienceafrique.fr/results_phase1.php

2. Akinterinwa, A., Osemeahon, S. A., Nkafamiya, I. I., Dass, P. M. (2015). Formulation of Emulsion Paint from a Copolymer Composite of Dimethylol Urea/Polystyrene. Chemistry and Materials Research, 7(7), 20-26. 
3. Akinyemi, B. A., Olamide, O., \& Oluwasogo, D. (2019). Formaldehyde free particleboards from wood chip wastes using glutaraldehyde modified cassava starch as binder. Case Studies in Construction Materials, 11, e00236. doi: 10.1016/j.cscm.2019.e00236

4. Al-Kadhemy, M. F. H., Rasheed, Z. S., \& Salim, S. R. (2016). Fourier transform infrared spectroscopy for irradiation coumarin doped polystyrene polymer films by alpha ray. Journal of Radiation Research and Applied Sciences, 9(3), 321-331. doi: 10.1016/j.jrras.2016.02.004

5. Arendt, W. D., McBride, E. L., \& Hanes, R. D. (2014). New dibenzoate plasticizer blends for PVC applications. Journal of Vinyl and Additive Technology, 20(3), 137-142. doi: 10.1002/vnl.21343

6. Arendt, W. D., McBride, E., \& Conner, M. M. (2014). Use of Dibenzoate Plasticizers in Pressure Sensitive Adhesives. Retrieved from https://www.pstc.org/i4a/pages/index.cfm?pageID=4491

7. Barrueso-Martínez, M. L., del Pilar Ferrándiz-Gómez, T., Romero-Sánchez, M. D., \& Martín-Martínez, J. M. (2003). Characterization of eva-based adhesives containing different amounts of rosin ester or polyterpene tackifier. The Journal of Adhesion, 79(8-9), 805-824. doi: $10.1080 / 00218460309547$

8. Chau, V. V., Bunge, F., Duffy, J., \& Hood, L. (2011). Advances in Thermal Insulation of Extruded Polystyrene Foams. Cellular Polymers, 30(3), 137-155.

9. Cortes, S. (2010). Theory and Interpretation of Infrared spectroscopy spectra. Retrieved from https://personal.utdallas.edu/ scortes/ochem/OChem_Lab1/recit_notes/ir_presentation.pdf

10. Duan, H., Qiu, T., Guo, L., Ye, J., Yuan, Y., \& Li, X. (2016). The aminolysis of styrene-maleic anhydride copolymers for a new modifier used in urea-formaldehyde resins. International Journal of Adhesion and Adhesives, 66, 138-146. doi: 10.1016/j.ijadhadh.2016.01.003

11. El, S., Koraichi, S., Latrache, H., \& Hamadi, F. (2012). Scanning Electron Microscopy (SEM) and Environmental SEM: Suitable Tools for Study of Adhesion Stage and Biofilm Formation. Scanning Electron Microscopy. doi: 10.5772/34990

12. Elbadawi, M., Osman, Z., Paridah, T., Nasroun, T., \& Kantiner, W. (2015). Mechanical and Physical Properties of Particleboards made from Ailanthus Wood and UF resin Fortified by Acacias Tannins Blend. Journal of Materials and Environmental Sciences, 6(4), 1016-1021.

13. Ernest, Z. (2015, January 23). How can I distinguish functional group region and fingerprint region in a infrared spectrum? Retrieved from https://socratic.org/questions/how-can-i-distinguishfunctional-group-region-and-fingerprint-region-in-a-infrar

14. Ghani, A., Ashaari, Z., Bawon, P., \& Lee, S. H. (2018). Reducing formaldehyde emission of urea formaldehyde-bonded particleboard by addition of amines as formaldehyde scavenger. Building and Environment, 142, 188-194. doi: 10.1016/j.buildenv.2018.06.020

15. Hamidu, L. A. J., Aroke, U. O., Osha, O. A., ... Muhammad, I. M. (2019). Formulation and Characterization of Adhesive Produced From Polystyrene Waste Using Response Surface Optimization. Path of Science, 5(8), 2001-2009. doi: 10.22178/pos.49-2

16. Idris, U. D., Aigbodion, V. S., Gadzama, R. M., Abdullahi, J. (2011). Eco-Friendly (Watermelon Peels) Alternatives to Wood-based Particleboard Composites. Tribology in industry, 33(4), 173-181.

17. Labcompare. (n. d.). Infrared Spectroscopy (IR/FTIR). Retrieved October 10, 2019, from https://www.labcompare.com/Spectroscopy/165-Infrared-Spectroscopy-IRFTIR/?search=Infrared+Spectroscopy

18. Osemeahon, S. A., \& Dimas, B. J. (2014). Development of urea formaldehyde and polystyrene waste as copolymer binder for emulsion paint formulation. Journal of Toxicology and Environmental Health Sciences, 6(3), 75-88. doi: 10.5897/jtehs2013.0285 
19. Osemeahon, S. A., Barminas, J. T., \& Jang, A. L. (2013). Development of Waste Polystyrene as a binder for emulsion paint formulation II: Effect of different types of Solvent. Journal of Environmental Science, Toxicology and Food Technology, 5(4), 1-7.

20. Osemeahon, S. A., Barminas, J. T., \& Jang, A. L. (2013). Development of Waste Polystyrene as a binder for emulsion paint formulation II: Effect of different types of Solvent. Journal of Environmental Science, Toxicology and Food Technology, 5(4), 1-7.

21. Polymer Properties Database. (2015). Polystyrenes (GPPS, HIPS, EPS, SBR, SBS, ABS). Retrieved October 10, 2019, from https://polymerdatabase.com/polymer\%20classes/Polystyrene\%20type.html

22. Rouabah, F., Dadache, D., \& Haddaoui, N. (2012). Thermophysical and Mechanical Properties of Polystyrene: Influence of Free Quenching. ISRN Polymer Science, 2012, 1-8. doi: 10.5402/2012/161364

23. Rudawska, A. (2012). Adhesive Properties. Scanning Electron Microscopy. doi: 10.5772/37011

24. Sanches, N. B., Pedro, R., Diniz, M. F., Mattos, E. D. C., Cassu, S. N., \& Dutra, R. de C. L. (2013). Infrared Spectroscopy Applied to Materials Used as Thermal Insulation and Coatings. Journal of Aerospace Technology and Management, 5(4), 421-430. doi: 10.5028/jatm.v5i4.265

25. Santos, R. P., Oliveira Junior, M. S. de, Mattos, E. D. C., Diniz, M. F., \& Dutra, R. D. C. L. (2013). Study by FT-IR Technique and Adhesive Properties of Vulcanized EPDM Modified with Plasma. Journal of Aerospace Technology and Management, 5(1). doi: 10.5028/jatm.v5i1.162

26. Selamat, M. E., Sulaiman, O., Hashim, R., Hiziroglu, S., Nadhari, W. N. A. W., Sulaiman, N. S., \& Razali, M. Z. (2014). Measurement of some particleboard properties bonded with modified carboxymethyl starch of oil palm trunk. Measurement, 53, 251-259. doi: 10.1016/j.measurement.2014.04.001

27. Silva, F. B. M., Vianna, R. F., \& Neubert, E. I. (2014). Study of Adhesion Properties of Natural Rubber Based Pressure Sensitive Adhesive with Variation of Tackifier Resin and Plasticizers Agents. Retrieved from https://pdfs.semanticscholar.org/78ed/e59a22f0762a6a82d25bafcbdab84711b1a0.pdf

28. WebSpectra. (2019). Table of IR Absorptions. Retrieved October 10, 2019, from https://webspectra.chem.ucla.edu/irtable.html

29. Zhao, X., Peng, L., Wang, H., Wang, Y., \& Zhang, H. (2018). Environment-friendly urea-oxidized starch adhesive with zero formaldehyde-emission. Carbohydrate Polymers, 181, 1112-1118. doi: 10.1016/j.carbpol.2017.11.035 